\title{
Are Turkish universities ready for e-learning: A case of Hacettepe University Faculty of Letters
}

\author{
İrem Soydal ${ }^{\mathrm{a}}$, Gülten Alır ${ }^{\mathrm{b}}$ and Yurdagül Ünal ${ }^{\mathrm{a}, *}$ \\ ${ }^{a}$ Department of Information Management, Hacettepe University, Ankara, Turkey \\ ${ }^{\mathrm{b}}$ Department of Information Management, Ylldırım Beyazıt University, Ankara, Turkey
}

\begin{abstract}
Universities play an important role in lifelong learning. E-learning is one of the key elements in today's networked and knowledge oriented world. It is crucial to know whether the universities are ready to transform their courses to e-learning systems. In this paper the e-learning readiness of the academic staff of Hacettepe University Faculty of Letters (HUFL) is investigated. A 37-item questionnaire along with some demographic questions is used for obtaining the data. Results show that title might be a significant factor for e-learning readiness and in general, HUFL academic staff are not ready for the e-learning environment. The findings of this study will help to conduct a larger study throughout Turkey in order to determine a model for course of action for transition to an e-learning system.
\end{abstract}

Keywords: E-learning readiness, higher education, academic staff readiness

\section{Introduction}

E-learning is one of the hot topics on the agenda in Turkey. Lots of e-learning projects are being developed and different e-learning tools are being used around Turkey. Generally universities are taking a close interest to the topic. For most of the institutions the key element of migrating to e-learning is budget. However, the initial concern should be the readiness of the institution with all of its counterparts, such as, faculty and students. It is important to analyze all different aspects of e-learning, determine the deficiencies and close the gaps in order to be able to use e-learning systems effectively.

Hacettepe University is one of the most prestigious, oldest and largest universities in Turkey. It was founded in 1967 and currently has 27,999 students and 3495 academic staff. There are 13 faculties and more than 60 research and teaching institutions within the university.

Faculty of Letters is the largest faculty at the university with 5489 students and 235 permanent and 99 temporary ${ }^{1}$ academic staff ( 334 in total). The aim of this preliminary study is to analyze the e-learning readiness of the academic staff that are working in the Hacettepe University Faculty of Letters (HUFL).

\footnotetext{
${ }^{*}$ Corresponding author: Yurdagül Ünal, Department of Information Management, Hacettepe University, 06800 Beytepe, Ankara, Turkey. E-mail: yurdagul@ hacettepe.edu.tr.

${ }^{1}$ Temporary staff consists of research assistants who actually work in other universities in Turkey, but temporarily being a part of HUFL by a special Faculty Training Programme carried out in the Turkish Universities.
} 


\section{Literature review}

There is a consensus about the definition of e-learning which stresses on the networked information and communication technology in teaching and learning [7,11]. Online learning, virtual learning, distributed learning, network and web-based learning, computer mediated instruction can also be used to define the same components of e-learning $[11,12]$. Whether networked or not, computers, tablets, mobile phones can be used for e-learning activities and these activities can be carried out by individuals or groups. In e-learning systems some applications such as, e-mail, online slides, simulations, games, mobile applications can also be used in order to create content, submit an assignment or test the students $[11,13]$.

Web 2.0 technologies, took e-learning systems one step forward. Theorists and researchers keep on developing new tools and systems parallel to the emerging web technologies. These developments attract the attention to online learning. As being a part of a traditional teaching environment face to face interaction with student is crucial for most of the teachers. However, online distance learning and face to face learning was compared in a study and no significant differences were found in terms of student's success [9]. In another study, two US universities were compared in terms face to face and online learning [5] and it was concluded that if the technological elements were balanced online learning would be more effective.

E-learning has huge opportunities, as well as challenges, for individuals and organizations. It can save time, cost and effort, and by enabling the remote access to the sources and contents. It can also satisfy educative needs of learners, supports the learning process and provides collaborative learning environments. However, these opportunities can turn into a big failure if the organization is not ready for e-learning with all of its components. Implementation of e-learning in the educational organizations is influenced by a number of factors, such as organizational, socio-cultural, intra- and interpersonal factors $[8,12]$. Four kinds of barriers were mentioned in the literature which are learners, teachers, curriculum and school [3]. Teachers are the key elements for adapting and implementing all the learning environment to an e-learning platform since they are directly engaged with students and course contents. They play an important role in curricular transformations, integrating e-learning technologies and adapting individuals to lifelong learning in a networked world in which knowledge plays a critical role [6].

E-learning is not a new topic for the researchers, but never lost its popularity. Akaslan and Law [1] mentioned some barriers concerning the implementation of e-learning in universities. They investigated the readiness and training needs for e-learning systems of teachers working in the higher education institutes associated with the science of electricity in Turkey which consist of 417 different programs. They examined the e-learning readiness with a 41 -item web based survey which is based on Kaur and Abas' conceptual model of e-learning (see Fig. 1) [10]. The results of the study showed that the academic staff has confidence and positive attitudes towards e-learning. Akaslan and Law [2] also applied their e-learning readiness survey to the students of same programme and although their findings showed that the students were ready enough for e-learning, they also need training on e-learning related issues. The need of training on e-learning for the lecturers was also emphasized in the study.

Another survey based study was conducted in Faculty of Education in Near East University and the results showed that almost half of the respondents used e-learning systems before. It was also concluded that the academic staff of sample faculty was ready for e-learning [15]. E-learning readiness researches are not only limited to the higher education. The e-learning readiness of 148 primary and secondary school teachers in Hong Kong was also examined in a different study [14]. It was concluded that, al- 


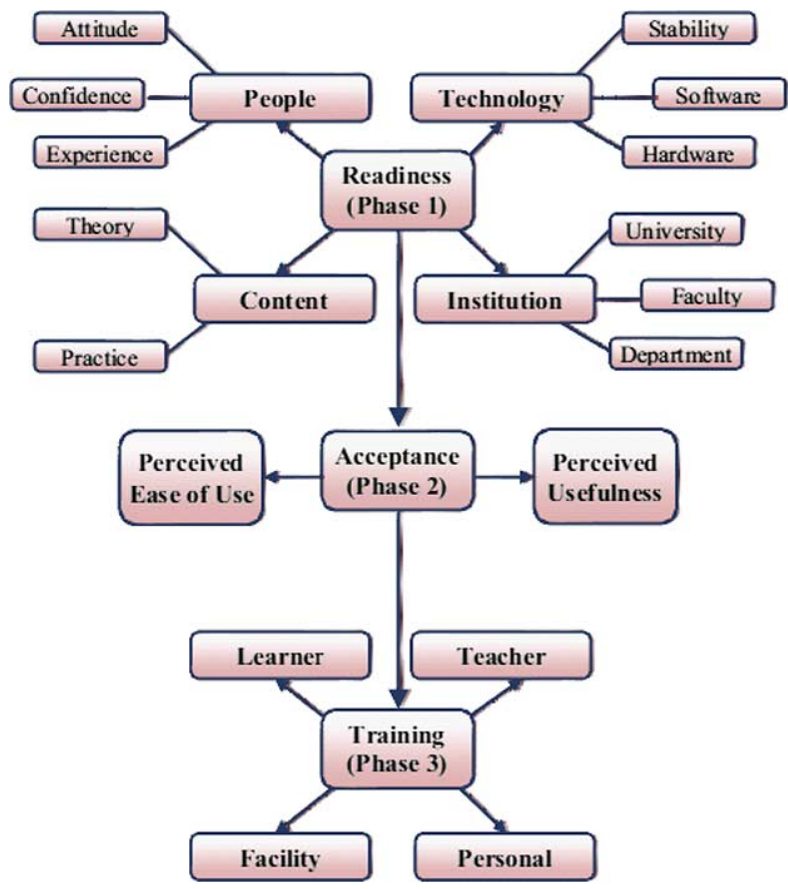

Fig. 1. The conceptual model of e-learning readiness survey (source: [1]). (Colors are visible in the online version of the article; http://dx.doi.org/10.3233/ISU-2012-0659.)

though lots of investments were done for the information technologies in schools, teachers in Hong Kong were still at the beginning stage of employing e-learning and its requirements into their daily curriculum.

\section{Research methodology}

Transforming the course contents into an e-learning system is one of the currently debated topics in some departments of HUFL. Time and extra efforts that will be needed to fulfill this process cannot be predicted easily. It is important to understand the perceptions of academic staff for e-learning who will be the number one actors of this new environment. The main goal of this preliminary study is to understand the level of readiness of the HUFL academic staff.

This paper addresses the following research questions:

- Does the academic staff of HUFL ready for e-learning?

- Do the participants tend to accept or reject e-learning?

- Are there any differences among the participants regarding their genders, ages, titles and departments in terms of accepting/rejecting e-learning?

- Is there any need for training in the implementation of e-learning?

To be able to determine the readiness level, a 37-item survey was employed to the 334 academic staff working in HUFL. Participants were asked to report their perceptions on readiness for e-learning. The questionnaire was developed by Akaslan and Law [1] and based on a conceptual model of the readiness for e-learning which assesses the perceived readiness in three phases namely, Readiness, Acceptance and Training. Survey examines four main factors, indicating the readiness of participants for e-learning, 
Table 1

E-learning readiness survey

\begin{tabular}{|c|c|c|}
\hline Category & Item no. & Item description \\
\hline \multirow[t]{26}{*}{ Readiness } & 1 & I am satisfied with my university network. \\
\hline & 2 & I use the Internet as information source. \\
\hline & 3 & I use e-mail as the main communication tool with my students and colleagues. \\
\hline & 4 & $\begin{array}{l}\text { I use office software (e.g., Microsoft Office, Open Office, etc.) for content delivery } \\
\text { and demonstration. }\end{array}$ \\
\hline & 5 & I use social network sites (e.g., Facebook, Twitter, etc.). \\
\hline & 6 & I use softwares related to my research field (e.g., Matlab, SPSS, etc.). \\
\hline & 7 & I use instant Messaging (e.g., MSN, Yahoo, etc.). \\
\hline & 8 & I use computers confidently. \\
\hline & 9 & I use web browsers (e.g., Internet Explorer, Google Chrome) confidently. \\
\hline & 10 & I use search engines (e.g., Google, MSN Search) confidently. \\
\hline & 11 & I use digital file management tools confidently. \\
\hline & 12 & I use tools to create learning materials confidently. \\
\hline & 13 & I have information about what e-learning is. \\
\hline & 14 & I have enough information and competency to prepare e-learning materials. \\
\hline & 15 & I feel that I am ready to integrate e-learning in my teaching. \\
\hline & 16 & I have enough time to prepare e-learning materials. \\
\hline & 17 & I believe my students will like e-learning. \\
\hline & 18 & The top-level administration understands what e-learning is. \\
\hline & 19 & The top-level administration supports the use of e-learning. \\
\hline & 20 & I believe e-learning is applied in my department. \\
\hline & 21 & I believe e-learning is applied in my faculty. \\
\hline & 22 & I believe e-learning is applied at my university. \\
\hline & 23 & E-learning can enhance the quality of the theoretical part of the my research field. \\
\hline & 24 & E-learning can enhance the quality of the practical part of the my research field. \\
\hline & 25 & E-learning can be applied to the theoretical part of the my research field. \\
\hline & 26 & E-learning can be applied to the practical part of the my research field. \\
\hline \multirow[t]{6}{*}{ Acceptance } & 27 & I believe that e-learning can improve the quality of my teaching. \\
\hline & 28 & I believe that using e-learning can increase my productivity. \\
\hline & 29 & I believe that e-learning is useful for my research. \\
\hline & 30 & $\begin{array}{l}\text { I believe that e-learning enables me to accomplish my teaching more effectively than } \\
\text { the traditional classroom-based approach. }\end{array}$ \\
\hline & 31 & I believe that it is easy for me to use e-learning. \\
\hline & 32 & I believe that my students find it easy to use e-learning. \\
\hline \multirow[t]{5}{*}{ Training } & 33 & I do not need training on e-learning. \\
\hline & 34 & My students do not need training on e-learning. \\
\hline & 35 & Technical and administrative personals do not need training on e-learning. \\
\hline & 36 & The facilities of university are sufficient for e-learning. \\
\hline & 37 & $\begin{array}{l}\text { To what extent do you support the integration of e-learning in your } \\
\text { department/program if your institution seems to be ready for e-learning? }\end{array}$ \\
\hline
\end{tabular}

which are technology, content, institution and people. Table 1 shows the parts and items of the survey that was used to obtained data.

Participants reported their perceptions on these e-learning related items with a five-point Likert-scale where 1 being "strongly disagree" and 5 being "strongly agree". Aydın and Taş̧̧ı's [4] identification of 


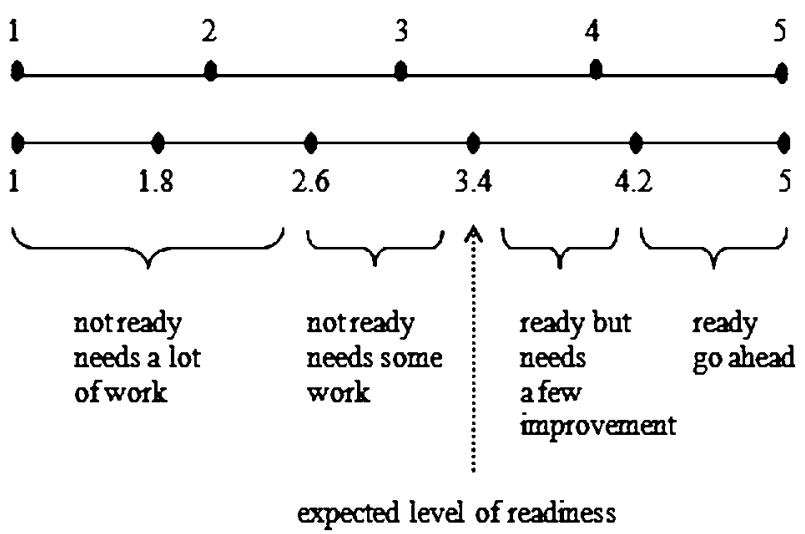

Fig. 2. E-learning readiness assessment model (source: [4]).

"expected level of readiness" for e-learning which is defined as the mean score of 3.40 was adopted in order to evaluate the survey results. This assessment model is based on the four intervals of five-point Likert-scale and suggests 0.8 (4 intervals/5 categories) as the critical level (see Fig. 2).

The study has some restrictions that need to be taken into consideration while interpreting the results. The main restriction was the number of participants. A pen-and-paper survey was intended to be handed in person to all of the academic staff in HUFL. However almost half of the staff could/did not give feedback due to their limited times, hectic working schedules, and so on. The other restriction was the unbalanced distribution of academic staff both in terms of titles and their numbers according to departments. Because of these limitations some departments may not be represented well enough and it would be better to bear in mind that some results could change slightly with a larger sample.

\section{Findings and discussion}

\subsection{Descriptive findings}

As mentioned earlier the universe of our study was defined as the academic staff of HUFL $(N=334)$. The staff were visited in person and data were obtained from $158(47 \%)$ academic staff from 16 different departments of HUFL. 55\% (87) of the respondents were female and $45 \%$ (71) were male. 56\% (88) of the respondents were younger than 35 years, $22 \%$ (34) were between 35-44 years, 18\% (28) were 4554 years and 5\% (8) were older than 55 years of age. These results show that most of the participants were under 45 years of age.

Total number of academic staff in HUFL and the ratio of respondents according to their titles ( $N$ is the total number of staff in HUFL that as the related title) can be seen in Table 2. The responses of the survey reflect almost half of the Associate and Assistant Professors, Lecturers and Research Assistants of the whole HUFL academic staff.

$30 \%$ of respondents (60 of 158) were Lecturers, Assistant or Associate Professors whose teaching activities were relatively more intense than other academic staff. ${ }^{2}$

\footnotetext{
${ }^{2}$ Participants were asked to mark their main responsibility among three choices; "teaching, "research" or "administration". $68 \%$ (41) of the respondents that reveal "teaching" as that their main responsibility were Associate and Assistant Professors and Lecturers. 87\% (68) of Professors and Research Assistants indicated their main responsibility as research or administration (total number of responses for this question was 138).
} 
Table 2

Distribution of titles of respondents

\begin{tabular}{lrrc}
\hline Title & $N$ & $n$ & $\%$ \\
\hline Professor & 58 & 14 & 24.1 \\
Associate Professor & 37 & 17 & 45.9 \\
Assistant Professor & 35 & 20 & 57.1 \\
Lecturer & 42 & 23 & 54.8 \\
Research Assistant & 157 & 83 & 52.9 \\
Other & 5 & 1 & 20.0 \\
Total/Mean & 334 & 158 & 47.3 \\
\hline
\end{tabular}

Table 3

Means for e-learning readiness items

\begin{tabular}{rccccccc}
\hline Item & $N$ & $\bar{X}$ & SD & Item & $N$ & $\bar{X}$ & SD \\
\hline 1 & 157 & 3.2 & 1.1 & 20 & 156 & 2.2 & 1.1 \\
2 & 157 & 4.4 & 0.7 & 21 & 157 & 2.6 & 0.9 \\
3 & 158 & 4.4 & 0.7 & 22 & 155 & 2.9 & 0.9 \\
4 & 158 & 4.4 & 0.8 & 23 & 158 & 3.4 & 1.0 \\
5 & 158 & 3.3 & 1.4 & 24 & 158 & 3.2 & 1.1 \\
6 & 157 & 2.6 & 1.5 & 25 & 157 & 3.5 & 1.0 \\
7 & 157 & 3.0 & 1.5 & 26 & 157 & 3.2 & 1.1 \\
8 & 157 & 4.0 & 0.9 & 27 & 158 & 3.4 & 1.0 \\
9 & 158 & 4.4 & 0.7 & 28 & 158 & 3.3 & 1.0 \\
10 & 158 & 4.3 & 0.7 & 29 & 157 & 3.5 & 0.9 \\
11 & 156 & 3.6 & 1.1 & 30 & 158 & 3.0 & 1.1 \\
12 & 158 & 3.5 & 0.7 & 31 & 157 & 3.3 & 0.9 \\
13 & 158 & 3.2 & 1.1 & 32 & 158 & 3.3 & 0.9 \\
14 & 158 & 2.9 & 1.0 & 33 & 157 & 2.2 & 1.0 \\
15 & 156 & 2.9 & 1.1 & 34 & 157 & 1.9 & 0.8 \\
16 & 157 & 2.4 & 0.9 & 35 & 158 & 1.8 & 0.9 \\
17 & 155 & 3.3 & 1.0 & 36 & 157 & 2.5 & 1.0 \\
18 & 156 & 2.6 & 0.9 & 37 & 150 & 3.6 & 1.1 \\
19 & 158 & 3.1 & 0.8 & Mean & 157 & 3.2 & 1.0 \\
\hline
\end{tabular}

The mean scores for e-learning related 37 items of the survey were displayed in Table 3. According to our assessment model, the scores for item 35 (Technical and administrative personals do not need training on e-learning, 1.8), 34 (My students do not need training on e-learning, 1.9), 33 (I do not need training on e-learning, 2.2), 20 (I believe e-learning is applied in my department, 2.2), 16 (I have enough time to prepare e-learning materials, 2.4) and 36 (The facilities of university are sufficient for $e$ learning, 2.5) revealed that in general, e-learning was not being used in the departments or individually by the academic staff of HUFL. Staff did not think they were ready to deal with e-learning materials and the results also pointed out the concerns of the academics about the lack of training (1-2.5: "not ready/confident, needs a lot of work"). On the other hand the mean scores for the items 2 (I use the Internet as information source, 4.4), 3 (I use e-mail as the main communication tool with my students and colleagues, 4.4), 4 (I use office software (e.g., Microsoft Office, Open Office, etc.) for content delivery and demonstration, 4.4), 9 (I use web browsers (e.g., Internet Explorer, Google Chrome) confidently, 4.4) 
and 10 (I use search engines (e.g., Google, MSN Search) confidently, 4.3) showed that academic staff of HUFL are confident to use basic web and office applications (4.2-5: "ready/confident, go ahead").

A Chi-Square test was conducted for each e-learning readiness item to evaluate the statistical significance of differences among the genders, ages and titles of the respondents.

Findings show gender differences is not significant in terms of e-learning readiness except 8 (I use computers confidently, $\chi^{2}=13.572, p=0.009$ ) which indicates male academic staff is more confident $(\bar{X}=4.2, \mathrm{SD}=0.8)$ than women $(\bar{X}=3.8, \mathrm{SD}=0.9)$ while using computers.

Age differences also affect the opinions of the respondents for a few e-learning readiness items. There are statistically significant differences among the ages of the respondents and the mean scores of the item 5 (I use social network sites (e.g., Facebook, Twitter, etc.), $\chi^{2}=49.970, p=0.000$ ), 8 (I use computers confidently, $\chi^{2}=37.409, p=0.010$ ), 9 (I use web browsers (e.g., Internet Explorer, Google Chrome) confidently, $\chi^{2}=26.243, p=0.003$ ), 10 (I use search engines (e.g., Google, MSN Search) confidently, $\chi^{2}=37.014, p=0.001$ ). The mean scores show that the respondents between 25-34 years of age gives higher points to these items (highest means assigned by this age group for these items differ between 3.8 and 4.6). This can be interpreted as younger academic staff is more confident while using Internet and office software.

Mean scores for the titles of the respondents differ slightly more than that of gender and age. There are statistically significant differences between respondents' title and the item 5 (I use social network sites (e.g., Facebook, Twitter, etc.), $\chi^{2}=52.337, p=0.000$ ), 9 (I use web browsers (e.g., Internet Explorer, Google Chrome) confidently, $\left.\chi^{2}=20.282, p=0.027\right), 14$ (I have enough information and competency to prepare e-learning materials, $\chi^{2}=55.065, p=0.000$ ), 15 ( I feel that I am ready to integrate e-learning in my teaching, $\left.\chi^{2}=48.729, p=0.000\right), 27$ (I believe that e-learning can improve the quality of my teaching, $\chi^{2}=34.199, p=0.025$ ), 33 (I do not need training on e-learning, $\chi^{2}=40.971, p=0.004$ ) and 36 (The facilities of university are sufficient for e-learning, $\chi^{2}=59.695$, $p=0.000)$. According to mean scores for the item 5 and 9 research assistants $(\bar{X}=3.8, \mathrm{SD}=1.3$; $\bar{X}=4.5, \mathrm{SD}=0.6$, respectively), for the items $14,15,27$ and 33 associate professors $(\bar{X}=3.6, \mathrm{SD}=$ $0.9 ; \bar{X}=3.7, \mathrm{SD}=0.8 ; \bar{X}=4.1, \mathrm{SD}=1.0 ; \bar{X}=2.8, \mathrm{SD}=1.3$, respectively) and for the item 36 professors $(\bar{X}=3.8, \mathrm{SD}=1.0)$ assigned the highest scores. These scores suggest that the critical mass could be associated professors who appear to be more ready for an e-learning environment than the other academic staff in HUFL. It is observed from the mean scores that 55\% (45) of research assistants indicate their perceptions as "neutralize" for the item 36 which makes us think that they may not be familiar enough to the university to discover its facilities or the competency for the e-learning environment.

\subsection{Readiness levels according to the departments}

The departments of HUFL ranging from History to Linguistics, Information Management to Psychology. All the departments have different teaching rituals and different expectations form their teaching environment. Findings also support this prediction. The results of Kruskal-Wallis Test reveals that the difference among the departments in terms of mean scores that they assigned for 24 of 37 e-learning readiness items were statistically significant (items $1-7,12-17,20,22-28,30,35$ and 37; $p<0.05$ ).

Table 4 shows the distribution of HUFL academic staff according to their departments where $N$ being the total number of academic staff that works in the related department and $\mathrm{n}$ being the number of respondents. As it is seen from the table, especially most of the Linguistics departments (French Language and Literature 100\%, American Culture and Literature 85.7\%, English Language and Literature $67.7 \%$, Translation and Interpretation 50\%) were represented with more than half of their populations. 
Table 4

Distribution and mean scores of respondents and according to their departments

\begin{tabular}{lrrrrrr}
\hline Department & \multicolumn{1}{c}{$n$} & \multicolumn{1}{c}{$\%$} & \multicolumn{1}{c}{ X } & SD & Comment \\
\hline Philosophy (PHI) & 23 & 8 & 34.8 & 2.6 & 0.3 & Not ready, needs a lot of work \\
Anthropology (ANT) & 8 & 6 & 75.0 & 2.8 & 0.4 & \\
French Language and Literature (FRE) & 9 & 9 & 100.0 & 2.9 & 0.3 & \\
History of Art (HistA) & 21 & 16 & 76.2 & 3.0 & 0.2 & \\
Turkish Language and Literature (TUR) & 32 & 8 & 25.0 & 3.0 & 0.3 & \\
English Language and Literature (ENG) & 31 & 21 & 67.7 & 3.1 & 0.3 & \\
English Linguistics (EngL) & 14 & 3 & 21.4 & 3.2 & 0.4 & \\
Psychology (PSI) & 23 & 10 & 43.5 & 3.2 & 0.3 & \\
German Language and Literature (GER) & 18 & 7 & 38.9 & 3.3 & 0.3 & \\
Translation and Interpretation (TRA) & 28 & 14 & 50.0 & 3.3 & 0.2 & \\
History (HIS) & 28 & 11 & 39.3 & 3.3 & 0.3 & \\
American Culture and Literature (AME) & 14 & 12 & 85.7 & 3.4 & 0.3 & Expected level \\
Archaeology (ARC) & 10 & 2 & 20.0 & 3.4 & 0.6 & \\
Sociology (SOC) & 27 & 9 & 33.3 & 3.4 & 0.3 & \\
Turkish Folklore (TurF) & 27 & 3 & 11.1 & 3.4 & 0.5 & \\
Information Management (IM) & 21 & 19 & 90.5 & 3.6 & 0.3 & Ready, but needs a few improvement \\
\hline
\end{tabular}

The departments of Information Management, History of Art and Anthropology have also high response rates $(90.5 \%, 76.2 \%$ and $75 \%$, respectively).

Mean scores displayed in Table 4 reveal that the majority of HUFL are not ready for e-learning. The departments of Philosophy, Anthropology and French Language and Literature have the lowest elearning readiness scores. Especially the result for Department of French Language and Literature is remarkable since its entire staff responded the survey. The highest score belongs to the Department of Information Management which could be thought as normal because of its familiarity to the electronic environment.

As mentioned in Table 1, items were categorized in the survey under three sections called Readiness, Acceptance and Training. The mean scores of departments according to these categories were displayed in Table 5.

Mean scores for three categories showed that - although most of the departments (except Anthropology, French Language and Literature, English Linguistics, English Language and Literature, History of Art and Turkish Language and Literature) were on or above the expected level of readiness for the Readiness category- all the departments thought they need to be trained for the e-learning environment. This situation can be observed more clearly from Fig. 3.

The gap between the expected score and the mean scores for the Training category is very obvious in Fig. 3. This means almost all the departments does not feel themselves comfortable in terms of e-learning and its applications. Some departments such as, Anthropology, French Language and Literature, History of Art and Turkish Language and Literature seems like they are not so much eager about e-learning. Not only Readiness or Training scores but also the Acceptance scores were low for these departments. The reason of this could be the nature of their field. It may hard for them to transfer the course contents to the electronic environment and academic staff might prefer face to face interaction with the students. Another possibility for the low scores of Acceptance could be the lack of knowledge on what e-learning exactly is. 
Table 5

Mean scores of three categories according to departments

\begin{tabular}{lccc}
\hline Departments & \multicolumn{3}{c}{ Categories } \\
\cline { 2 - 4 } & Readiness & Acceptance & Training \\
\hline GER & 3.5 & 3.5 & 2.5 \\
AME & 3.6 & 3.8 & 2.4 \\
ANT & 2.8 & 2.8 & 2.5 \\
ARC & 3.4 & 3.5 & 3.3 \\
IM & 3.8 & 3.7 & 2.6 \\
PHI & 3.4 & 3.4 & 2.2 \\
FRE & 2.7 & 2.5 & 2.7 \\
EngL & 3.0 & 2.8 & 2.1 \\
ENG & 3.3 & 3.3 & 2.1 \\
TRA & 3.4 & 3.6 & 2.3 \\
PSI & 3.4 & 3.4 & 2.1 \\
HistA & 3.1 & 2.9 & 2.5 \\
SOC & 3.5 & 3.5 & 2.6 \\
HIS & 3.4 & 3.3 & 2.6 \\
TUR & 3.1 & 3.0 & 2.5 \\
TurF & 3.6 & 3.9 & 1.9 \\
Mean & 3.3 & 3.3 & 2.4 \\
\hline
\end{tabular}

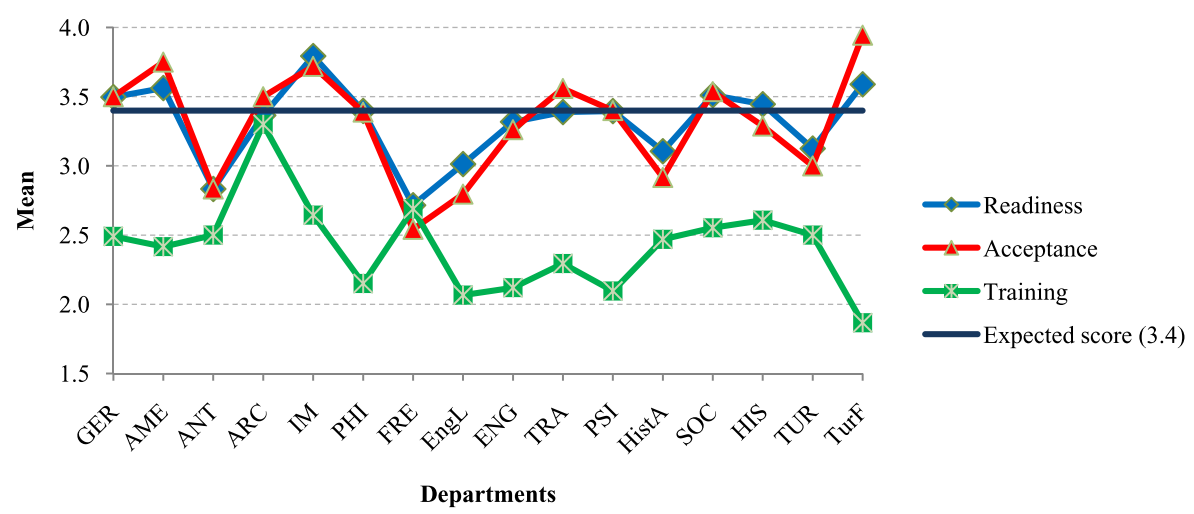

Fig. 3. Readiness, Acceptance and Training scores of the departments. (Colors are visible in the online version of the article; http://dx.doi.org/10.3233/ISU-2012-0659.)

In a sense these results contradict with Akaslan and Law's [1] findings, which could considered as normal because of the nature of different research fields like literacy and electrical engineering. In contrast to their findings it can be said that the mean score (3.2, see Table 3) of all items of e-learning readiness survey shows that HUFL academic staff does not have considerably positive perceptions on e-learning. Yet they seem to be eager to be trained on e-learning related issues.

\section{Conclusions and recommendations}

E-learning is an emerging issue both in the world and in Turkey. In general, universities are the most convenient test and implementation area for e-learning and most of the universities in Turkey conducting 
projects to move their contents and teaching environments to e-learning systems.

In this study the e-learning readiness of HUFL academic staff was tested with an paper-and-pen survey with 37 items that measures the perceptions of the participants in terms of Readiness, Acceptance and Training. The effect of gender, age and titles to e-learning readiness perceptions of the respondents was also tested. For most of the items statistically significant differences in terms of gender, age or title were not observed. Yet, it was found out that gender was the least effective variable where as title was the most decisive one. The results also showed that younger academic staff was more confident while using Internet and office software. The mean scores also suggest that the critical mass could be associated professors during the implementation trials of e-learning environments who appear to be more ready than the other academic staff in HUFL.

Differences among different departments in terms of e-learning perceptions were also tested in the study. It was found out that for most of the items there was statistically significant differences among the mean scores of the departments. This could be as normal since HUFL has different academic units with different research, teaching and learning rituals. However it should be taken into consideration that the reason of this result could also be the unbalanced distribution of respondents among the departments.

One of the remarkable results that should be noted was the gap between the expected mean score level and the opinions of respondents for the Training category. Findings showed obviously that academic staff of HUFL need training on e-learning. This means a structural training program would be necessary before taking a step further in e-learning implementations.

Electronic environment is changing rapidly and the results of such studies could differ in different circumstances. For instance, HUFL academic staff - whose research area is linguistics and social sciences seems not to be ready for e-learning. On the contrary, a similar study conducted within the academics working in electrical engineering field reveals that those researchers and lecturers are ready enough and have positive perceptions for e-learning. It is important to make these kinds of studies with larger samples and determine a course of action for transition to an e-learning system. It is also prominent to identify the e-learning readiness situation for the students.

\section{References}

[1] D. Akaslan and E.L.-C. Law, Measuring teachers' readiness for e-learning in higher education institutions associated with the subject of electricity in Turkey, in: Proceedings of the IEEE Global Engineering Education Conference (EDUCON) Learning Environments and Ecosystems in Engineering Education, Amman, Jordan, April 4-6, 2010, pp. 481-490.

[2] D. Akaslan and E.L.-C. Law, Measuring student e-learning readiness: a case about the subject of electricity in higher education institutions in Turkey, in: Proceedings of the 10th International Conference on Advances in Web Based LearningICWL 2011, Hong Kong, China, LNCS, Vol. 7048, Springer, Berlin, 2011, pp. 209-218.

[3] M. Assareh and B. Hosseini, Barriers to e-teaching and e-learning, Proc. Comput. Sci. 3 (2011), 791-795.

[4] C.H. Aydın and D. Taşçı, Measuring readiness for e-learning: reflections from an emerging country, Educ. Technol. Soc. 8 (2005), 244-257.

[5] D.M. Bender, B.J. Wood and J.D. Vredevoogd, Teaching time: distance education versus classroom instruction, Amer. J. Dist. Educ. 18 (2004), 103-114.

[6] P. Bonanno, Developing an instrument to assess teachers' readiness for technology-enhanced learning, in: Proceedings of the 14th International Conference on Interactive Collaborative Learning, Piešt'any, Slovakia, 21-23 September 2011.

[7] C. Brooks, J. Greer, E. Melis and C. Ullrich, Combining ITS and eLearning technologies: opportunities and challenges, in: Proceedings of the ITS'2006, M. Ikeda, K.D. Ashley and T.-W. Chan, eds, LNCS, Vol. 4053, Springer, Heidelberg, 2006, pp. 278-287.

[8] B. Hegarty and M. Perman, Approaches and implications of eLearning adoption in relation to academic staff efficacy and working practice final report, Universal College of Learning, 2005, available at: http://cms.steo.govt.nz/NR/rdonlyres/ 8C221A73-CF28-4CC9-83E8-B8FD7D9C1164/0/ALETfinalReport251006.pdf (retrieved 11 January 2012). 
[9] N. Jahng, D. Krug and Z. Zhang, Student achievement in online distance education compared to face-to-face education, Eur. J. Open Dist. E-Learn. 1 (2007), available at: http://www.eurodl.org/materials/contrib/2007/Jahng_Krug_Zhang.htm.

[10] K. Kaur and Z.W. Abas, An assessment of e-learning readiness at Open University Malaysia, in: Proceedings of the International Conference on Computers in Education (ICCE), Melbourne, Australia, November 30-December 4, 2004.

[11] S. Naidu, E-Learning: A Guidebook of Principles, Procedures and Practices, Commonwealth Educational Media Center for Asia, New Delhi, 2006.

[12] G.M. Piskurich (Ed.), The AMA Handbook of E-Learning: Effective Design, Implementation, and Technology Solutions, AMACOM, New York, 2003.

[13] M. Sasikumar, E-learning: opportunities and challenges, 2006, available at: http://www.cdacmumbai.in/design/corporate site/override/pdf-doc/e-learning.pdf (retrieved 11 January 2012).

[14] K.K.T. So, The e-learning readiness of teachers in Hong Kong, in: Proceedings of the 5th IEEE International Conference on Advanced Learning Technologies (ICALT'05), IEEE Computer Society, Washington, DC, USA, 2005, pp. 806-808.

[15] M. Tezer and H. Bicen, Üniversite öğretim elemanlarinin e-eğitim sistemlerine yönelik hazır bulunuşluğu [The preparations university teachers towards e-education systems], in: Proceedings of the International Educational Technology Conference, Anadolu University, Turkey, 2008. 
Copyright of Information Services \& Use is the property of IOS Press and its content may not be copied or emailed to multiple sites or posted to a listserv without the copyright holder's express written permission. However, users may print, download, or email articles for individual use. 